\title{
Bedroom media, sedentary time and screen-time in children: a longitudinal analysis
}

Andrew J Atkin ${ }^{1 *}$, Kirsten Corder ${ }^{1,2}$ and Esther M F van Sluijs ${ }^{1,2}$

\begin{abstract}
Background: Having electronic media in the bedroom is cross-sectionally associated with greater screen-time in children, but few longitudinal studies exist. The aim of this study was to describe longitudinal patterns of ownership and examine cross-sectional and longitudinal associations of bedroom media with children's sedentary behaviour.

Methods: Data are from the Sport, Physical activity and Eating behaviour: Environmental Determinants in Young people (SPEEDY) study, collected at 3 time-points: baseline (2007, $T_{0}$; age $10.3 \pm 0.3$ years), 1-year ( $\left.T_{1 y}\right)$ and 4-year ( $\left.\mathrm{T}_{4 y}\right)$ follow-up. For each assessment, 1512 (44.9\% male), 715 (41.0\% male), and 319 (48.3\% male) participants provided valid accelerometer data. Outcome variables were accelerometer-assessed sedentary time and self-reported screen-time. The presence of a television or computer in the bedroom was self-reported by participants and a combined bedroom media score calculated as the sum of such items. Cross-sectional and longitudinal associations between bedroom media and each outcome were examined using multi-level linear regression.
\end{abstract}

Results: Bedroom TV ownership fell from $70.9 \%$ at $\mathrm{T}_{0}$ to $42.5 \%$ at $\mathrm{T}_{4 \mathrm{y}}$. Having a TV in the bedroom (beta; $\left.95 \% \mathrm{Cl}^{*} 100, \mathrm{~T}_{0}:-1.17 ;-1.88,-0.46 . \mathrm{T}_{1 \mathrm{y}}:-1.68 ;-2.67,-0.70\right)$ and combined bedroom media $\left(\mathrm{T}_{0}:-0.76 ;-1.26,-0.27\right.$. $\left.T_{1 y}:-0.79 ;-1.51,-0.07\right)$ were negatively associated with objectively measured weekly sedentary time at $T_{0}$ and $T_{1 y}$. Having a computer in the bedroom (beta; $95 \% \mathrm{Cl}, \mathrm{T}_{0}: 0.15 ; 0.02,0.29 . \mathrm{T}_{4 y}: 0.35 ; 0.10,0.60$ ) and combined bedroom media ( $\left.T_{0}: 0.09: 0.01,0.18 . T_{4 y}: 0.20 ; 0.05,0.34\right)$ were positively associated with screen-time at $T_{0}$ and $T_{4 y}$. Relative to participants without a computer throughout the study, children that had a computer in their bedroom at $\mathrm{T}_{0}$ but not at $\mathrm{T}_{4 y}$ (beta; $95 \% \mathrm{Cl}$ for change in screen-time: -8.02; $-12.75,-3.29$ ) reported smaller increases in screen-time.

Conclusions: The bedroom media environment changes with age and exhibits a complex relationship with children's sedentary behaviour. Modifying children's bedroom media environment may impact upon screen-time but appears unlikely to influence overall sedentary time.

Keywords: Television, Children, Family, Sedentary behaviour, Accelerometer

\section{Introduction}

Sedentary behaviours, such as watching television (TV) and using a computer, are highly prevalent during childhood [1-4] and may be adversely associated with cardiometabolic health, though evidence from longitudinal and experimental research is limited [5-10]. In the UK, and other countries, public health guidelines recommend

\footnotetext{
*Correspondence: aa595@medschl.cam.ac.uk

'UKCRC Centre for Diet and Activity Research (CEDAR), MRC Epidemiology

Unit, University of Cambridge School of Clinical Medicine, Institute of

Metabolic Science, Cambridge Biomedical Campus, Box 285, Cambridge CB2 OQQ, UK

Full list of author information is available at the end of the article
}

that children should minimise the amount of time spent being sedentary for prolonged periods [11,12].

Research into the determinants of sedentary behaviour enables the identification of at-risk populations and modifiable factors that may be targeted within intervention programmes $[13,14]$. Contemporary thinking on the determinants of health behaviour advocates the application of an ecological framework to reflect the influence of factors operating at individual, social and environmental levels [15]. In children, the influence of home and familial characteristics on sedentary behaviour patterns has been a key area of research [16-19], particularly regarding the impact of electronic media (TV, computers, video games consoles) in the

\section{Biomed Central}

(c) 2013 Atkin et al.; licensee BioMed Central Ltd. This is an open access article distributed under the terms of the Creative Commons Attribution License (http://creativecommons.org/licenses/by/2.0), which permits unrestricted use, distribution, and reproduction in any medium, provided the original work is properly cited. 
bedroom. Approximately two-thirds of children in the US and UK have a TV in their bedroom $[20,21]$ and this has been associated with higher levels of screen-time (watching $\mathrm{TV}$, using a computer), reduced sleep and increased risk of overweight [20,22-24]. The removal of such devices from the bedroom has been recommended [9,25-27]. However, few longitudinal studies have examined how electronic media ownership changes with age and whether changes in the bedroom media environment are associated with changes in sedentary behaviour patterns. Previous research examining the association between presence of a TV in the bedroom and total sedentary time has been conducted in pre-schoolers [28] or adolescents [29] or produced mixed findings [30]. Therefore, the aims of the current study were to (1) describe changes in bedroom media ownership over 4 years, from ages $9 / 10$ to $13 / 14$ years (3 waves of assessment) (2) examine the cross-sectional association of bedroom media with objectively measured sedentary time and self-reported screen-time at three time-points and (3) examine the association of changes in bedroom media ownership with changes in objectively measured sedentary time and self-reported screen-time.

\section{Methods}

\section{Study design and setting}

The Sport, Physical Activity, and Eating Behaviour: Environmental Determinants in Young People (SPEEDY) study is a population based longitudinal, cohort study investigating factors associated with physical activity, sedentary behaviour and dietary patterns in children from the county of Norfolk, UK [31]. Ethical approval was obtained from the University of East Anglia research ethics committee.

\section{Participants}

Full details of participant recruitment and procedures for baseline data collection in SPEEDY have been reported previously [31]. From 227 eligible schools (those with >12 children in year 5), 157 were approached and 92 were recruited. At participating schools, all children in school year 5 and their parents $(n=3619)$ were sent an invitation pack. In total, 2064 children provided parental consent and were measured at baseline $(57 \%$ of those invited).

\section{Data collection procedures}

Participants were invited to participate on three separate occasions: baseline ( $\mathrm{T}_{0}$; age 9/10y; April-July 2007), 1year follow-up ( $\mathrm{T}_{1 y}$; age 10/11y; April-July 2008), and 4year follow-up ( $\mathrm{T}_{4 y}$; age 13/14y; April-July 2011). Where possible, timing of follow-up assessments were matched to baseline. At baseline, trained research assistants visited schools to take physical measurements, administer child questionnaires, and fit accelerometers. Participants were requested to return the accelerometer one week later; Participation at $\mathrm{T}_{0}$ was prerequisite for recruitment to either of the subsequent waves of assessment. At $\mathrm{T}_{1 \mathrm{y}}$, study information sheets and consent forms were mailed to all 2064 initial participants [2]. Those who consented were mailed an accelerometer and a detailed instruction sheet. Participants were asked to wear the accelerometer for one week and to return it by mail, using an addressed, pre-paid envelope. At $\mathrm{T}_{4 \mathrm{y}}$, all participants with a valid home address from $T_{1 y}(n=1964)$ were sent information sheets and consent forms. Through local administrative authorities, we ascertained the number of participants attending each secondary school in Norfolk, but our original consent did not allow us to trace individual participants. We presented the study in Year 9 assemblies at secondary schools attended by at least five original participants. Consent forms were returned to the study office by mail. Subsequent measurements were taken at school following similar procedures as at baseline. To increase recruitment, an extra invitation letter was sent home prior to the holiday (July 2011), resulting in an additional 62 participants being assessed by mail, following the same methodology as $\mathrm{T}_{1 \mathrm{y}}$.

\section{Objectively measured sedentary time}

At each assessment, sedentary time was measured objectively using an Actigraph (GT1M; Pensacola, FL) accelerometer, [32,33] set to record at 5-second epochs. Children were instructed to wear the monitors during waking hours for 7 days and to remove them while bathing, showering and swimming. For quality control purposes, participants also received an accelerometer diary and instructed to indicate when the monitor was taken off and for what reason. Accelerometer data were analysed using a batch processing program (MAHUffe; http://www.mrc-epid.cam.ac.uk/research/resources/materials-transfer-disclaimer/physical-activity-downloads/). A count threshold of $<100$ counts per minute was used to define sedentary time $[34,35]$. Periods of $\geq 10$ minutes of consecutive zero counts $[2,36]$ and days with $<500 \mathrm{mi}-$ nutes of recording between 6 am-11 pm were excluded $[1,2]$. A minimum of 3 days of valid accelerometer data, including 1 weekend day, was required for inclusion in the analysis. To optimise specificity between outcome and exposure measures, data collected during school hours ( 9 am-3 pm on weekdays) were excluded from the analysis.

\section{Self-reported screen-time}

At $\mathrm{T}_{0}$ and $\mathrm{T}_{4 \mathrm{y}}$, leisure-time screen-time was assessed using a slightly modified version of a child self-report questionnaire, the Youth Physical Activity Questionnaire 
(YPAQ; [37]), which is based on the Children's Leisure Activities Study Survey (CLASS; [38]). Separate items assessed time spent using a computer (including the internet; 1 week test-retest reliability ICC for CLASS items = 0.53 ) and watching TV (including video/DVD; 1 week test-retest reliability ICC $=0.93$ ). Participants indicated on which of the previous 7 days they had engaged in these behaviours and the average duration of participation. Items referred to behaviours occurring outside of school hours but did not distinguish recreational from educational use. Weekly hours of screen-time was calculated by multiplying the frequency by the duration and summing the total for weekdays and weekend days. Time spent playing video games was not included in our screen-time calculation because the survey made no distinction between 'active' and 'passive' video games consoles.

\section{Bedroom media}

The presence of a television or computer in the bedroom was self-reported by participants at $\mathrm{T}_{0}, \mathrm{~T}_{1 \mathrm{y}}$ and $\mathrm{T}_{4 \mathrm{y}}$. A combined bedroom media score (range 0-2) was calculated as the sum of the TV and computer items. Categorical variables indicating changes in bedroom TV and computer ownership (constantly absent, constantly present, $\mathrm{T}_{0}$ absent $/ \mathrm{T}_{4 \mathrm{y}}$ present, $\mathrm{T}_{0}$ present $/ \mathrm{T}_{4 \mathrm{y}}$ absent) and combined bedroom media items (stable, decrease, increase) from $\mathrm{T}_{0}$ to $\mathrm{T}_{4 \mathrm{y}}$ were derived.

\section{Covariates}

All covariates were assessed at baseline. Age and sex were self-reported. Height and weight were measured by trained research assistants and used to calculate body mass index (BMI, $\mathrm{kg} / \mathrm{m}^{2}$ ); weight status (normal weight/ overweight) was determined using age and sex specific thresholds [39]. Postal code was used to determine urban/rural location of participants home [40]. Four density profiles were collapsed into a dichotomous variable (city / town and fringe: urban; hamlets and isolated dwellings / villages: rural). Because different markers of socioeconomic status (SES) may exhibit differential associations with sedentary behaviour [41], we derived a composite score (range 0-3) to better reflect the underlying SES construct; the score comprised parentreported age at leaving full time education $(\leq 16$ years coded 0 ; $>16$ years coded 1 ), car ownership (no coded 0 ; yes coded 1), and house ownership (rental coded 0 ; own/buying coded 1). Participants were assigned to low (score 0/1), mid (score 2) or high (score 3) SES groups.

\section{Statistical analysis}

Analyses were conducted using Stata (Stata, College Station, TX) in 2013. Baseline characteristics for those included and lost to follow-up were compared using $t$ tests and $X^{2}$ tests. Sex differences in sedentary time and screen-time were examined using $t$ tests and MannWhitney tests respectively. Within time-point differences in bedroom media ownership according to sex, weight status, SES and urban/rural location were assessed using $X^{2}$ tests. In the cross-sectional and longitudinal analyses, multi-level linear regression was used to examine the association of bedroom media with sedentary time and screen-time. Estimates of screen-time, but not change in screen-time, were non-normally distributed and therefore transformed (Box-Cox) prior to analysis. Regression models were adjusted for school-level clustering, sex, age, BMI, SES and urban/rural location. Interaction terms were used to assess potential effect modification by sex.

For descriptive purposes (Table 1), accelerometer derived sedentary time is presented as the proportion of wear time spent sedentary and weighted hours per week spent sedentary ( 5 *weekday +2 weekend). In crosssectional analyses, the outcome was the proportion of wear time spent sedentary. In longitudinal analyses, the outcome was change in the proportion of wear time spent sedentary, calculated as follows: $\left[\left(\mathrm{T}_{4 \mathrm{y}}\right.\right.$ sedentary time $/ \mathrm{T}_{4 \mathrm{y}}$ wear time $\left.) \times 100\right]-\left[\left(\mathrm{T}_{0}\right.\right.$ sedentary time $/ \mathrm{T}_{0}$ wear time) $\times 100$ ]. In both cases, outcome variables were continuous and normally distributed.

\section{Results}

Of the 2064 children that provided parental consent at baseline, valid accelerometer data was obtained for 1512 ( $\mathrm{T}_{0}, 73 \%$ of baseline participants), $715\left(\mathrm{~T}_{1 \mathrm{y}}, 35 \%\right)$, and $319\left(\mathrm{~T}_{4 \mathrm{y}}, 15 \%\right)$ participants respectively. Data on selfreported screen-time was provided by $1745\left(\mathrm{~T}_{0}, 85 \%\right)$ and $373\left(\mathrm{~T}_{4 \mathrm{y}}, 18 \%\right)$ participants respectively. With the exception of the sample providing screen-time data at $\mathrm{T}_{0}$, participants included in cross sectional analyses were of higher SES than those that were excluded (all $\mathrm{p}<0.05)$. The sample providing valid accelerometer data at $\mathrm{T}_{1 \mathrm{y}}(\mathrm{p}=0.01)$ and $\mathrm{T}_{4 \mathrm{y}}(\mathrm{p}<0.01)$ also had lower BMI than participants who were excluded from analyses. Additionally, participants with valid accelerometer data at $\mathrm{T}_{1 \mathrm{y}}$ were more likely to be female $(\mathrm{p}=0.01)$, younger $(\mathrm{p}=0.05)$ and live in a rural location $(\mathrm{p}=0.007)$ than participants without valid data. Data on objectively measured sedentary time and self-reported screen-time at $\mathrm{T}_{0}, \mathrm{~T}_{1 \mathrm{y}}$ and $\mathrm{T}_{4 \mathrm{y}}$ are presented in Table 1.

The proportion of participants with a TV or computer in the bedroom is presented in Figures 1 and 2. Overall, $70.9 \%$ of participants had a TV in their bedroom at $\mathrm{T}_{0}$, declining to $42.5 \%$ at $\mathrm{T}_{4 \mathrm{y}}$. Relative to their respective reference groups, children who were overweight $\left(\mathrm{T}_{0}(\mathrm{p}\right.$ for $\left.\left.\mathrm{X}^{2}=0.009\right) ; \mathrm{T}_{1 \mathrm{y}}(\mathrm{p}=0.002)\right)$, living in an urban area $\left(\mathrm{T}_{0}\right.$ $\left.(\mathrm{p}<0.001) ; \mathrm{T}_{1 \mathrm{y}}(\mathrm{p}=<0.001) ; \mathrm{T}_{4 \mathrm{y}}(\mathrm{p}=0.026)\right)$ or from families of low SES $\left(\mathrm{T}_{0}(\mathrm{p}<0.001) ; \mathrm{T}_{1 \mathrm{y}}(\mathrm{p}<0.001)\right)$ were more likely to have a TV in the bedroom. The presence of a computer in the bedroom increased from $21.7 \%$ at $\mathrm{T}_{0}$ 
Table 1 Children's objectively measured sedentary time and self-reported screen-time at 3 time-points (values are mean \pm SD unless stated otherwise)

$\begin{array}{lll}T_{0}(n=1512) & T_{1 y}(n=715) & T_{4 y}(n=319) \\ 44.9 \% \text { male, } 10.3(0.31) y & 41.0 \% \text { male, } 11.2(0.3) y & 48.3 \% \text { male, } 14.3(0.3) y\end{array}$

Accelerometer Sedentary time, $\%$ of wear time

All

$62.2 \pm 6.3$

Boys

$$
61.1 \pm 6.7
$$

Girls

$63.1 \pm 5.9^{* *}$

Accelerometer Sedentary time, Hrs/wk

All

$$
34.9 \pm 5.3
$$

$34.6 \pm 5.6$

Boys

$35.2 \pm 5.1^{*}$

$\mathrm{T}_{0}(\mathrm{n}=1745)$

$44.0 \%$ male, $10.3(0.3) y$

Girls
$70.2 \pm 6.5$

$62.4 \pm 6.4$

$69.6 \pm 7.2$

$64.3 \pm 6.0^{* *}$

$70.8 \pm 5.6$

, Hrs/wk, median (IQR)

Se

All

$6.9(2.9-14.8)$

$15.1(8.5-26.0)$

Boys

$8.1(3.3-16.6)$

$15.2(8.9-25.5)$

Girls

$6.1(2.6-13.2)^{* *}$

$15.0(8.3-26.0)$

$\mathrm{T}_{0}$, April-July 2007; $\mathrm{T}_{1 y^{\prime}}$ April-July 2008; $\mathrm{T}_{4 y^{\prime}}$ April-July 2011; y, years; $\mathrm{SD}$, standard deviation; IQR, inter-quartile range.

*Within time-point difference between sexes $(P<0.05)$

**Within time-point difference between sexes $(P<0.01)$
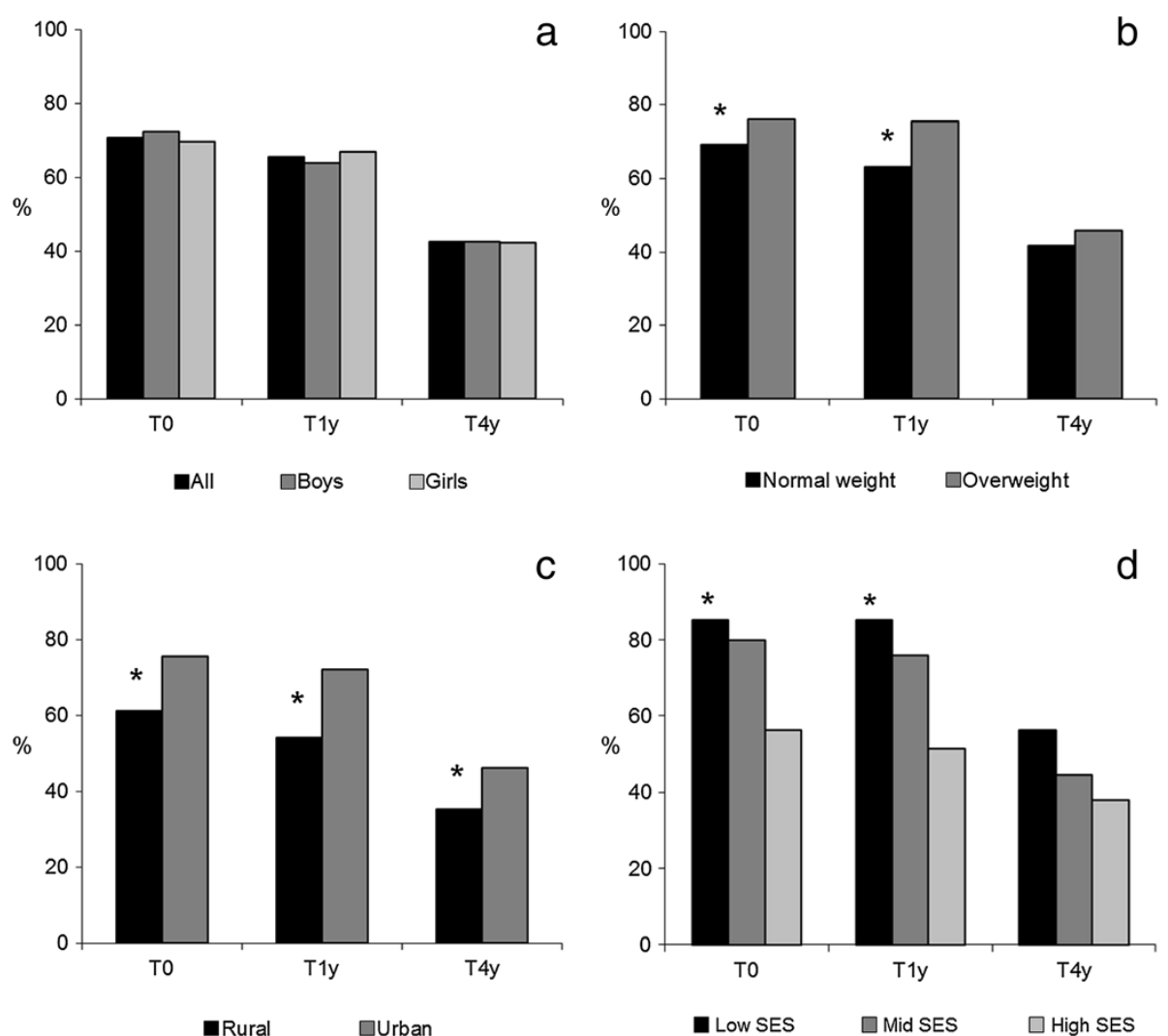

Figure 1 Proportion of children with a TV in their bedroom, stratified by (a) sex, (b) weight status, (c) urban/rural location, (d) socioeconomic status. T0, April-July 2007 ( $n=1808) ;$ T1y, April-July 2008 ( $n=849) ;$ T4y, April-July 2011 ( $n=438)$.

*Difference in proportions within time-point $(p<0.05)$. 

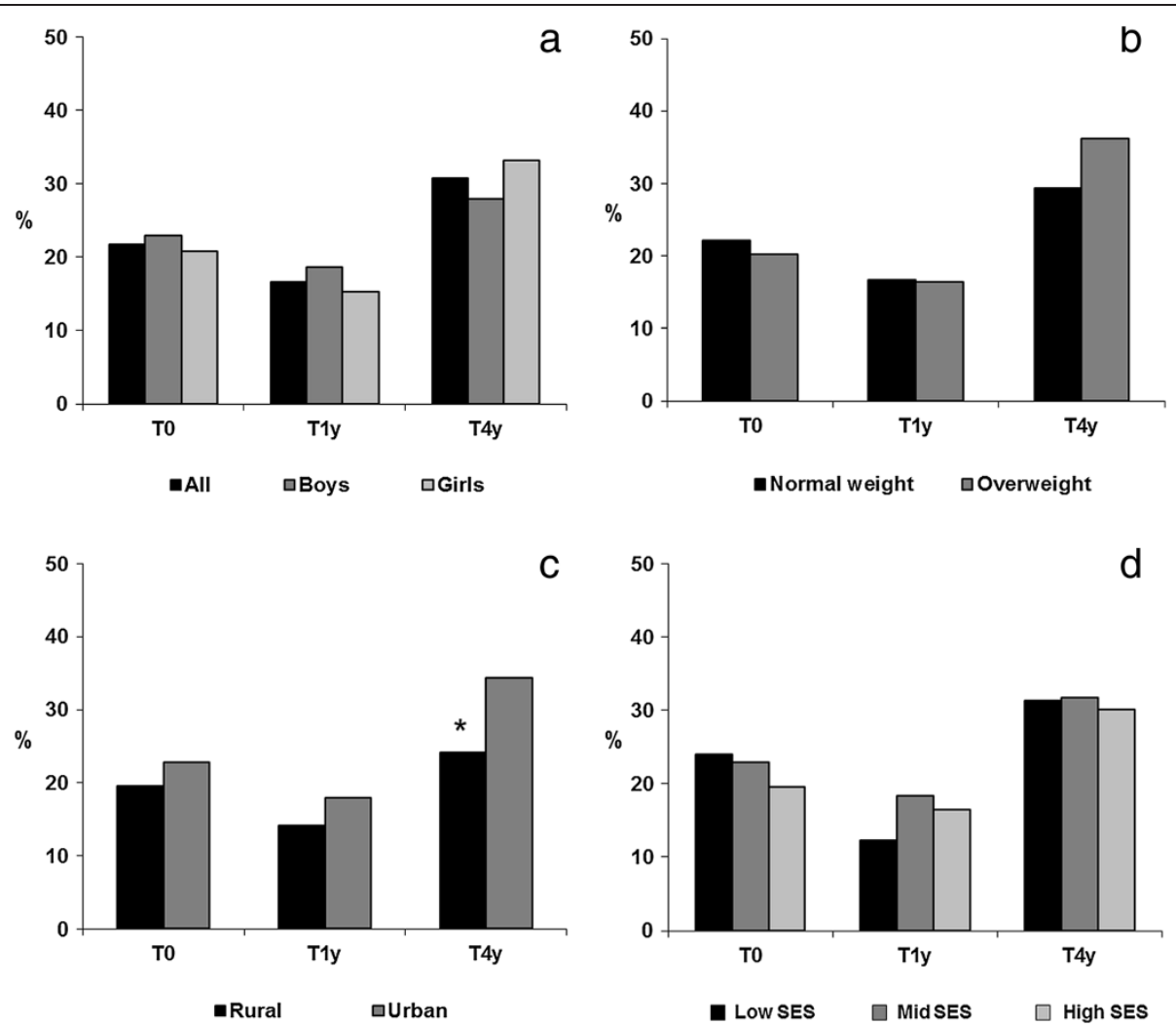

Figure 2 Proportion of children with a computer in their bedroom, stratified by (a) sex, (b) weight status, (c) urban/rural location, (d) socioeconomic status. T0, April-July 2007 ( $n=1808)$; T1y, April-July 2008 ( $n=849) ;$ T4y, April-July 2011 ( $n=438$ ).

*Difference in proportions within time-point $(p<0.05)$.

to $30.8 \%$ at $\mathrm{T}_{4 \mathrm{y}}$. At $\mathrm{T}_{4 \mathrm{y}}$ only, the proportion of participants with a computer in their bedroom was higher in children from urban compared to rural locations $(\mathrm{p}=0.027)$. The proportion of participants with 0,1 , or 2 electronic media in the bedroom is presented in Figure 3. From $T_{0}$ to $T_{4 y}$, the proportion of children with no electronic media in the bedroom increased from $25.2 \%$ to $48.9 \%$. Concurrently, there was a small increase in the proportion of children with both a TV and computer in the bedroom $\left(\mathrm{T}_{0}: 17.8 \%\right.$; $\mathrm{T}_{4 \mathrm{y}}$ : 22.2\%). Differences in combined bedroom media score were observed by weight status $\left(\mathrm{T}_{1 \mathrm{y}} \mathrm{p}=0.017\right)$, urban/rural location $\left(\mathrm{T}_{0}(\mathrm{p}<0.001) ; \mathrm{T}_{1 \mathrm{y}}(\mathrm{p}<0.001) ; \mathrm{T}_{4 \mathrm{y}}(\mathrm{p}=0.009)\right)$ and SES $\left(\mathrm{T}_{0}(\mathrm{p}<0.001) ; \mathrm{T}_{1 \mathrm{y}}(\mathrm{p}<0.001)\right)$.

Cross-sectional and longitudinal associations of bedroom media with sedentary time and screen-time are presented in Tables 2 and 3 respectively. At $\mathrm{T}_{0}$ and $\mathrm{T}_{1 \mathrm{y}}$, having a TV in the bedroom and total bedroom media were negatively associated with objectively measured sedentary time. Having a computer in the bedroom and combined bedroom media score was positively associated with self-reported screen-time at $\mathrm{T}_{0}$ and $\mathrm{T}_{4 \mathrm{y}}$. Longitudinally, no significant associations were observed between changes in bedroom TV or computer ownership and change in objectivelymeasured sedentary time. Having a computer in the bedroom at $T_{0}$ but not at $T_{4 y}$ was negatively associated with change in screen-time; participants in this group reported smaller increases in screen-time than those in the reference group. Tests for interaction by sex revealed that cross-sectional associations between bedroom media and objectively-measured sedentary time were typically stronger in girls, though few interactions attained significance (Additional file 1). No evidence of interaction with sex was observed for self-report outcomes or in longitudinal models.

\section{Discussion}

\section{Main findings}

This study examined change in the electronic media environment of the bedroom over 4 years and the association of bedroom media with objectively measured sedentary time and self-reported screen-time. A complex pattern of findings emerged, likely reflecting both the true nature of the association between bedroom media and children's sedentary behaviours and contemporary developments in electronic media ownership. Over 4 years, bedroom TV ownership declined substantially whilst the presence of a computer in the bedroom rose. In cross-sectional analyses, there was evidence of a 


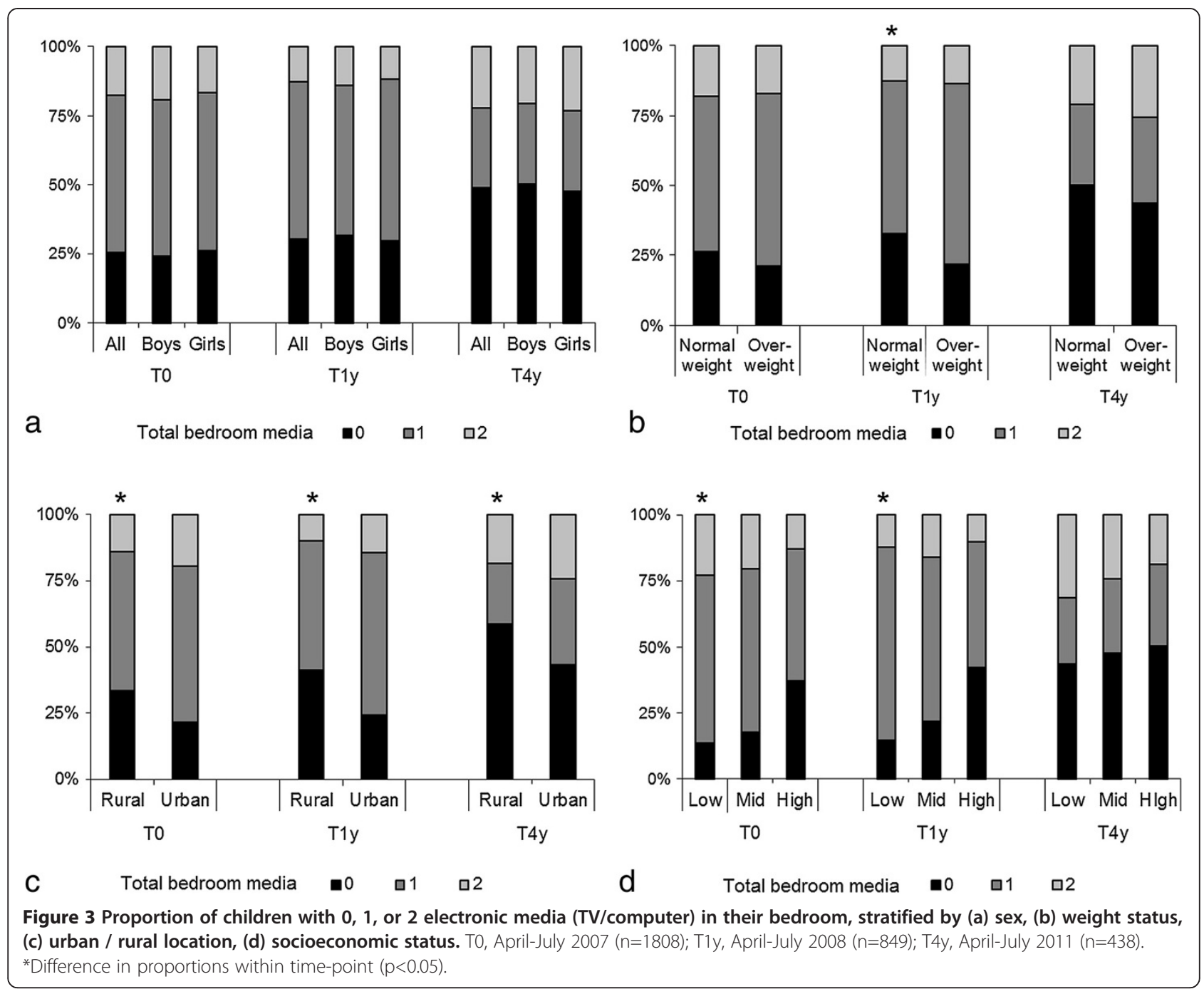

Table 2 Cross-sectional association of bedroom media with objectively measured sedentary time and self-reported screen-time

\begin{tabular}{|c|c|c|c|c|c|c|c|c|c|}
\hline & \multicolumn{3}{|c|}{$T_{0}(n=1512)$} & \multicolumn{3}{|c|}{$T_{1 y}(n=715)$} & \multicolumn{3}{|c|}{$T_{4 y}(n=319)$} \\
\hline & \multicolumn{2}{|c|}{$\beta(95 \% \mathrm{Cl})$} & $P$ & \multicolumn{2}{|c|}{$\beta(95 \% \mathrm{Cl})$} & $P$ & \multicolumn{2}{|c|}{$\beta(95 \% \mathrm{Cl})$} & $P$ \\
\hline Television in bedroom & -1.17 & $(-1.88,-0.46)$ & $<0.01$ & -1.68 & $(-2.67,-0.70)$ & $<0.01$ & 0.21 & $(-1.23,1.65)$ & 0.77 \\
\hline Computer in bedroom & -0.49 & $(-1.25,0.27)$ & 0.21 & 0.29 & $(-0.91,1.49)$ & 0.64 & 1.25 & $(-0.32,2.82)$ & 0.12 \\
\hline \multirow[t]{3}{*}{ Combined bedroom media } & -0.76 & $(-1.26,-0.27)$ & $<0.01$ & -0.79 & $(-1.51,-0.07)$ & 0.03 & 0.51 & $(-0.40,1.42)$ & 0.27 \\
\hline & \multicolumn{3}{|c|}{$T_{0}(n=1745)$} & & & & \multicolumn{3}{|c|}{$T_{4 y}(n=373)$} \\
\hline & \multicolumn{2}{|c|}{$\beta(95 \% \mathrm{Cl})$} & \multicolumn{4}{|l|}{$P$} & \multicolumn{2}{|c|}{$\beta(95 \% \mathrm{Cl})$} & $P$ \\
\hline \multicolumn{10}{|l|}{ Self-reported screen-time $^{\dagger}$} \\
\hline Television in bedroom & 0.06 & $(-0.07,0.19)$ & 0.35 & & & & 0.22 & $(-0.02,0.46)$ & 0.07 \\
\hline Computer in bedroom & 0.15 & $(0.02,0.29)$ & 0.02 & & & & 0.35 & $(0.10,0.60)$ & $<0.01$ \\
\hline Combined bedroom media & 0.09 & $(0.01,0.18)$ & 0.03 & & & & 0.20 & $(0.05,0.34)$ & $<0.01$ \\
\hline
\end{tabular}

Models adjusted for clustering in schools, sex, age, body mass index, socio-economic status and urban/rural location.

*Outcome variable: Weekly proportion of wear time spent sedentary; Beta coefficient $(95 \% \mathrm{Cl}) * 100$.

${ }^{\dagger}$ Outcome variable: Weekly hours of self-reported screen-time (Box-Cox transformed); Beta coefficient $(95 \% \mathrm{Cl})$. 
Table 3 Longitudinal association of change in bedroom media with change in sedentary time and self-reported screentime

\begin{tabular}{|c|c|c|c|c|c|c|c|c|}
\hline \multirow[b]{2}{*}{ Variable } & \multirow[b]{2}{*}{$\mathbf{n}$} & \multicolumn{3}{|c|}{ Sedentary time $(n=283)^{*}$} & \multirow[b]{2}{*}{$\mathbf{n}$} & \multicolumn{3}{|c|}{ Screen-time $(n=357) \dagger$} \\
\hline & & \multicolumn{2}{|c|}{$\beta(95 \% \mathrm{Cl})$} & \multirow[t]{2}{*}{$\mathbf{P}$} & & \multicolumn{2}{|c|}{$\beta(95 \% \mathrm{Cl})$} & \multirow[t]{2}{*}{$\mathbf{P}$} \\
\hline \multicolumn{7}{|l|}{ Television } & & \\
\hline Constantly absent & 90 & Ref & & & 112 & Ref & & \\
\hline Constantly present & 86 & 1.39 & $(-0.79,3.57)$ & 0.21 & 113 & 4.17 & $(0.18,8.15)$ & 0.04 \\
\hline$T_{0}$ absent $-T_{4 y}$ present & 36 & -0.57 & $(-3.25,2.1)$ & 0.68 & 38 & 3.59 & $(-1.89,9.07)$ & 0.20 \\
\hline$T_{0}$ present $-T_{4 y}$ absent & 71 & 0.59 & $(-1.64,2.82)$ & 0.61 & 94 & 0.82 & $(-3.38,5.01)$ & 0.70 \\
\hline \multicolumn{9}{|l|}{ Computer } \\
\hline Constantly absent & 164 & Ref & & & 196 & Ref & & \\
\hline Constantly present & 23 & 0.49 & $(-2.56,3.54)$ & 0.75 & 32 & 1.96 & $(-3.51,7.43)$ & 0.48 \\
\hline$T_{0}$ absent $-T_{4 y}$ present & 58 & 1.64 & $(-0.48,3.75)$ & 0.13 & 84 & 2.08 & $(-1.68,5.83)$ & 0.28 \\
\hline$T_{0}$ present $-T_{4 y}$ absent & 38 & 0.53 & $(-2.97,1.91)$ & 0.67 & 45 & -8.02 & $(-12.75,-3.29)$ & $<0.01$ \\
\hline \multicolumn{9}{|c|}{ Combined bedroom media } \\
\hline Stable & 126 & Ref & & & 155 & Ref & & \\
\hline Decrease & 80 & -0.43 & $(-2.39,1.53)$ & 0.67 & 102 & -1.88 & $(-5.62,1.87)$ & 0.33 \\
\hline Increase & 77 & 0.49 & $(-1.51,2.49)$ & 0.63 & 100 & 2.57 & $(-1.2,6.35)$ & 0.18 \\
\hline
\end{tabular}

Ref, reference group.

Models adjusted for clustering in schools, sex, age, body mass index, socio-economic status and urban/rural location.

*Outcome variable: Change in weekly proportion of wear time spent sedentary $\mathrm{T}_{4 \mathrm{y}}-\mathrm{T}_{0}$; Beta coefficient $(95 \% \mathrm{Cl})^{*} 100$.

${ }^{\dagger}$ Outcome variable: Change in weekly hours of self-reported screen-time $\mathrm{T}_{4 \mathrm{y}}-\mathrm{T}_{0}$; Beta coefficient $(95 \% \mathrm{Cl})$.

positive association between bedroom media and children's screen-time but associations with overall sedentary time were less clear. Longitudinal analysis indicated that removal of a computer from the bedroom may be a means of limiting the age-related increase in screentime, but changes in the bedroom media environment were not associated with changes in overall sedentary time.

\section{Comparison with other evidence and implications}

The observed increase in screen-time and overall sedentary time from $\mathrm{T}_{0}$ to $\mathrm{T}_{4 \mathrm{y}}$ is consistent with previous research indicating that sedentary behaviour increases as children age $[1,42]$. Reported screen-time in the current study was somewhat lower than has been reported previously in UK children; this may be due to temporal shifts in screen-time habits, contrasting sample characteristics or the application of different measurement tools [42] The extent to which the rise in overall sedentary time is attributable to increased screen-time or shifts in other behaviours, for example greater homework requirements or car use, remains unclear. More detailed characterisation of age-related changes in sedentary behaviour, that includes assessment of specific behaviours as well as overall sedentary time, will enable interventions to be developed and targeted more precisely.

The proportion of children with a TV in the bedroom decreased by approximately $30 \%$ points between $\mathrm{T}_{0}$ and $\mathrm{T}_{4 \mathrm{y}}$, whilst the proportion of children with a computer in the bedroom increased by approximately $10 \%$ points over the same period. Recent data from Ofcom (the independent regulator for the UK communications industries) also indicates a decline in the presence of TVs and a rise in the availability of the internet in children's bedrooms between 2007-2010, though the magnitude of change was smaller than that seen in the current study [21]. Findings may reflect age related changes in media preferences [21] but also broader societal patterns in electronic media ownership over the study period. In a 2011 survey, computers (including 'tablet' computers), e-book readers and mobile phones were listed above television sets as items that US children and adolescents had most interest in buying within the next 6-months [43]. Television viewing in the traditional sense (watching live or time shifted content on a television set delivered by broadcast signal or paid TV subscription) appears to be declining, as consumers increasingly utilise alternative devices (e.g. computers, games consoles) to access video content $[44,45]$. The evolution and uptake of electronic media, both portable and home-based, frequently outpaces the efforts of researchers to document trends and examine its impact upon behaviour and health. Going forward, researchers should recognise the multitude of platforms through which children may access audio-visual content and acknowledge the increasing portability and multifunctionality of new devices.

The proportion of participants with a TV or computer in the bedroom differed by socioeconomic status and by 
urban/rural location. Previous studies have reported that having a TV in the bedroom is typically more common amongst low SES families, whilst having a computer or internet access in the bedroom is more prevalent in higher SES groups [21,46]. The use of different markers to indicate SES, however, limits comparability between studies. An urban/rural divide in internet usage and connection speeds has been reported previously in the UK $[47,48]$ but we are unaware of any existing studies that have examined urban/rural differences in the bedroom media environment.

In this study, combined bedroom media score was positively associated with screen-time at $\mathrm{T}_{0}$ and $\mathrm{T}_{4 \mathrm{y}}$, consistent with previous research [18,49]. Interestingly, the positive association observed in this study appears to be driven predominantly by the presence of a computer in the bedroom, which was individually associated with screen-time at $\mathrm{T}_{0}$ and $\mathrm{T}_{4 \mathrm{y}}$. Considered alongside our finding that the presence of a computer in the bedroom increased from $\mathrm{T}_{0}$ to $\mathrm{T}_{4 \mathrm{y}}$, these data suggest that researchers must acknowledge emerging trends in electronic media ownership and avoid an overly restrictive focus solely upon TV [27]. In so doing, new instruments may be required to capture the diversity of electronic media used by young people. It may also be valuable to concurrently ascertain context of behaviour and postural allocation, as it may no longer be appropriate to infer posture on the basis of reported behaviour.

Unexpectedly, having a TV in the bedroom and combined bedroom media score were negatively associated with objectively measured sedentary time at $\mathrm{T}_{0}$ and $\mathrm{T}_{1 \mathrm{y}}$. There was some evidence that the negative association of bedroom media with sedentary time was stronger in girls than boys but interaction tests were mostly borderline significant. Previous studies have predominantly shown no association between having a TV in the bedroom and accelerometer-determined sedentary time and no evidence for interaction with sex $[28,30]$. Given the increasing use of accelerometry to assess sedentary time in epidemiological studies, further research on this question is likely and may provide some clarity. It is also of interest that cross-sectional analyses at $\mathrm{T}_{4 \mathrm{y}}$ identified (non-significant) positive associations between bedroom media and sedentary time. It is unclear whether this apparent switch in the direction of the association is arbitrary (associations were non-significant at $\mathrm{T}_{1 \mathrm{y}}$ and $\mathrm{T}_{4 \mathrm{y}}$ ), an artefact of study design, or reflects a changing pattern of influence as children age. Further studies exploring this potential interaction with age are required.

In longitudinal analyses, a smaller increase in screentime was observed in participants that reported having a computer in the bedroom at $\mathrm{T}_{0}$ but not at $\mathrm{T}_{4 \mathrm{y}}$. In most models, the associations between a change in bedroom media and change in sedentary time or screen-time were in the anticipated direction but did not attain statistical significance. Participant attrition may have resulted in reduced statistical power for these analyses. Numerous studies have advocated the removal of electronic media from children's bedrooms as a means of limiting screentime, [9,25-27] but experimental research exploring the efficacy of this approach is lacking. Findings of the current study provide some support for this strategy. However, important contextual information regarding the circumstances in which computers were removed from participants' bedrooms is lacking in our analysis. Moreover, qualitative work has indicated that children and parents may be resistant to the idea of removing electronic media from the bedroom once they have been installed [50]. Trials exploring the influence of removing electronic media from children's bedrooms should include process evaluations to understand the acceptability of this strategy for children and parents.

In the current study, we are not able to ascertain whether observed changes in the bedroom media environment were attributable to age-related changes in media preferences or broader societal changes in electronic media use over the study period. Uptake of information technology and communications media has grown rapidly in recent years [20,21]. Devices such as tablet computers and mobile phones are highly valued by adolescents and are an increasingly important means by which young people accumulate screen-time $[20,21,43]$. They are also portable and multifunctional, enabling the user to perform multiple tasks (e.g. gaming, using the internet, watching TV) simultaneously and without being tied to a specific location. Researchers need to recognise the broad range of electronic media used by young people, including the extent to which users may perform multiple tasks simultaneously, and be more explicit in gathering data on the contexts in which behaviours occur, rather than inferring context from the location of a particular device [26].

\section{Strengths and limitations}

The strengths of this study include its longitudinal design and the collection of objective and self-report data on sedentary behaviour in a large population-based sample of children. Repeated assessments on a single cohort enabled us to identify changes in behaviour and the bedroom media environment over time. Regression models were adjusted for a number of potentially confounding factors and interactions with sex were explored. A limitation is that video game consoles were not included in our assessment of the bedroom media environment or in our screen-time outcome. This is because we were unable to differentiate between active and passive games consoles in baseline assessments. In addition, we did not assess ownership of tablet computers or distinguish 
between desktop or laptop computers in our questionnaire. We addressed the potential limitation of differences in accelerometer wear between waves of assessment by deriving outcomes that were relative to recorded wear time at each time point. The response rate at $\mathrm{T}_{4 \mathrm{y}}$ was low and participants with higher BMI or from lower SES families were less likely to provide outcome data at $\mathrm{T}_{1 \mathrm{y}}$ and $\mathrm{T}_{4 \mathrm{y}}$, limiting generalizability of findings. Where appropriate, we conducted sensitivity analyses to examine the potential impact of selection bias by limiting the analytical sample to participants that provided complete data at all time points. In all cases, the direction and magnitude of associations were minimally affected (data not shown). Lastly, information on the covariates SES, BMI and urban/rural location of the home was collected at baseline only; it is possible that these factors may have changed over time, possibly resulting in misclassification.

\section{Conclusion}

In this study we found that there were notable changes in the electronic media environment of children's bedrooms over 4 years, and that the presence of bedroom media was more consistently associated with children's screen-time behaviour than overall sedentary time. In light of the rapid and continuing uptake of information and communications technology by young people, further research examining the context and content of electronic media use, and its impact upon behaviour and health, is essential.

\section{Additional file}

Additional file 1: Cross-sectional association of bedroom media with objectively measured sedentary time, stratified by sex.

\section{Competing interests}

The authors declare that they have no competing interests.

\section{Authors' contributions}

AJA conceived the analysis, performed data analysis and drafted the manuscript. KC contributed to study design, data acquisition and analysis, and critically reviewed the manuscript. EMFS contributed to study design, data acquisition and analysis, and critically reviewed the manuscript. All authors read and approved the final manuscript.

\section{Acknowledgements}

The work of Andrew J Atkin, Kirsten Corder, and Esther M F van Sluijs was supported, wholly or in part, by the Centre for Diet and Activity Research (CEDAR), a UK Clinical Research Collaboration Public Health Research Centre of Excellence (RES-590-28-0002). Funding from the British Heart Foundation, Economic and Social Research Council, Medical Research Council, the National Institute for Health Research, and the Wellcome Trust, under the auspices of the UK Clinical Research Collaboration, is gratefully acknowledged. The SPEEDY study was funded by the Medical Research Council (Unit Programme number MC_UU_12015/7, MC_UU_12015/3, MC_UU_12015/4) and the National Prevention Research Initiative, consisting of the following funding partners: British Heart Foundation; Cancer Research United Kingdom; Department of Health; Diabetes United Kingdom; Economic and Social Research Council; Medical Research Council; Health and
Social Care Research and Development Office for Northern Ireland; Chief Scientist Office, Scottish Government Health Directorates; Welsh Assembly Government; and World Cancer Research Fund. The SPEEDY study is a collaboration between the MRC Epidemiology Unit and the School of Environmental Sciences and the School of Medicine, Health Policy and Practice at the University of East Anglia, Norwich, UK. The contribution of our collaborators at the University of East Anglia in obtaining funding and ethical approval, data collection and data processing is gratefully acknowledged. We thank the schools, children, and parents for their participation, everyone who helped with the data collection and Norfolk Children's Services for invaluable input and support. In addition, we thank Kate Westgate and Stefanie Mayle from the physical activity technical team at the MRC Epidemiology Unit for their assistance in processing the accelerometer data.

\section{Author details}

${ }^{1}$ UKCRC Centre for Diet and Activity Research (CEDAR), MRC Epidemiology Unit, University of Cambridge School of Clinical Medicine, Institute of Metabolic Science, Cambridge Biomedical Campus, Box 285, Cambridge CB2 OQQ, UK. ${ }^{2}$ MRC Epidemiology Unit, University of Cambridge School of Clinical Medicine, Cambridge, UK.

Received: 26 July 2013 Accepted: 13 December 2013 Published: 17 December 2013

\section{References}

1. Basterfield L, Adamson AJ, Frary JK, Parkinson KN, Pearce MS, Reilly JJ: Longitudinal study of physical activity and sedentary behavior in children. Pediatrics 2011, 127:e24-e30.

2. Corder K, van Sluijs EM, Ekelund U, Jones AP, Griffin SJ: Changes in children's physical activity over 12 months: longitudinal results from the SPEEDY study. Pediatrics 2010, 126:e926-e935.

3. Foley LS, Maddison R, Jiang Y, Olds T, Ridley K: It's not just the television: survey analysis of sedentary behaviour in New Zealand young people. Int J Behav Nutr Phys Act 2012, 8:132.

4. Ruiz JR, Ortega FB, Martinez-Gomez D, Labayen I, Moreno LA, De Bourdeaudhuij I, Manios Y, Gonzalez-Gross M, Mauro B, Molnar D, Widhalm K, Marcos A, Beghin L, Castillo MJ, Sjostrom M: Objectively measured physical activity and sedentary time in European adolescents: the HELENA study. Am J Epidemiol 2011, 174:173-184.

5. Ekelund U, Brage S, Froberg K, Harro M, Anderssen SA, Sardinha LB, Riddoch C, Andersen LB: TV viewing and physical activity are independently associated with metabolic risk in children: the European youth heart study. PLoS Med 2006, 3:e488.

6. Ekelund U, Luan J, Sherar LB, Esliger DW, Griew P, Cooper A: Moderate to vigorous physical activity and sedentary time and cardiometabolic risk factors in children and adolescents. JAMA 2012, 307:704-712.

7. Chinapaw MJ, Proper KI, Brug J, van Mechelen W, Singh AS: Relationship between young peoples' sedentary behaviour and biomedical health indicators: a systematic review of prospective studies. Obes Rev 2011, 12:e621-e632.

8. Rey-Lopez JP, Vicente-Rodriguez G, Biosca M, Moreno LA: Sedentary behaviour and obesity development in children and adolescents. Nutr Metab Cardiovasc Dis 2008, 18:242-251.

9. Salmon J, Tremblay MS, Marshall SJ, Hume C: Health risks, correlates, and interventions to reduce sedentary behavior in young people. Am J Prev Med 2011, 41:197-206.

10. Tremblay MS, LeBlanc AG, Kho ME, Saunders TJ, Larouche R, Colley RC, Goldfield G, Connor Gorber S: Systematic review of sedentary behaviour and health indicators in school-aged children and youth. Int J Behav Nutr Phys Act 2011, 8:98.

11. Tremblay MS, LeBlanc AG, Janssen I, Kho ME, Hicks A, Murumets K, Colley RC, Duggan M: Canadian sedentary behaviour guidelines for children and youth. Appl Physiol Nutr Metab 2011, 36:59-64.

12. Start Active Stay Active: A Report on Physical Activity for Health from the Four Home countries' Chief Medical Officers. The Department of Health; 2011.

13. Marshall SJ, Ramirez E: Reducing sedentary behavior: a new paradigm in physical activity promotion. Am J Lifestyle Med 2011, 5:518-530.

14. Sallis JF, Owen N: Physical Activity and Behavioural Medicine. Thousand Oaks, CA: Sage; 1999. 
15. Sallis J, Owen N: Ecological Models of Health Behavior. In Heal Behav Heal Educ Theory, Res Pract. Volume 3rd. Edited by Glanz K, Rimer BK, Lewis FM. San Francisco, CA: Jossey-Bass; 2002:462-485.

16. Gorely T, Atkin AJ, Biddle SJ, Marshall SJ: Family circumstance, sedentary behaviour and physical activity in adolescents living in England: project STIL. Int J Behav Nutr Phys Act 2009, 6:33.

17. Hesketh K, Crawford D, Salmon J: Children's Television viewing and objectively measured physical activity: associations with family circumstance. Int J Behav Nutr Phys Act 2006, 3:36.

18. Pate RR, Mitchell JA, Byun W, Dowda M: Sedentary behaviour in youth. Br J Sports Med 2011, 45:906-913.

19. Uijtdewilligen L, Nauta J, Singh AS, van Mechelen W, Twisk JW, van der Horst K, Chinapaw MJ: Determinants of physical activity and sedentary behaviour in young people: a review and quality synthesis of prospective studies. Br J Sports Med 2011, 45:896-905.

20. Rideout VJ, Foehr UG, Roberts DF: Generation M2: Media in the Lives of 8-18 Year Olds. Kaiser Family Foundation; 2010. http://kff.org.

21. Ofcom: UK children's media literacy. http://stakeholders.ofcom.org.uk/ binaries/research/media-literacy/media-lit11/childrens.pdf.

22. Adachi-Mejia AM, Longacre MR, Gibson JJ, Beach ML, Titus-Ernstoff LT, Dalton MA: Children with a TV in their bedroom at higher risk for being overweight. Int J Obes (Lond) 2007, 31:644-651.

23. Hesketh K, Ball K, Crawford D, Campbell K, Salmon J: Mediators of the relationship between maternal education and children's TV viewing. Am J Prev Med 2007, 33:41-47.

24. Sisson SB, Broyles ST, Newton RL Jr, Baker BL, Chernausek SD: TVs in the bedrooms of children: does it impact health and behavior? Prev Med 2011, 52:104-108.

25. Schmidt ME, Haines J, O'Brien A, McDonald J, Price S, Sherry B, Taveras EM: Systematic review of effective strategies for reducing screen time among young children. Obesity 2012. doi: 10.10.

26. McKetta S, Rich M: The fault, dear viewer, lies not in the screens, but in ourselves: relationships between screen media and childhood overweight/obesity. Pediatr Clin North Am 2011, 58:1493-1508.

27. Jordan $A B$, Robinson $T N$ : Children, television viewing, and weight status: summary and recommendations from an expert panel meeting. Ann Am Acad Pol Soc Sci 2008, 615:119-132.

28. Dolinsky DH, Brouwer RJ, Evenson KR, Siega-Riz AM, Ostbye T: Correlates of sedentary time and physical activity among preschool-aged children. Prev Chronic Dis 2011, 8:A131.

29. Sirard JR, Laska MN, Patnode CD, Farbakhsh K, Lytle LA: Adolescent physical activity and screen time: associations with the physical home environment. Int J Behav Nutr Phys Act 2010, 7:82.

30. Van Sluijs EM, Page A, Ommundsen Y, Griffin SJ: Behavioural and social correlates of sedentary time in young people. Br J Sport Med 2010, 44:747-755.

31. Van Sluijs EMF, Skidmore PML, Mwanza K, Jones AP, Callaghan AM, Ekelund U, Harrison F, Harvey I, Panter J, Wareham NJ, Cassidy A, Griffin SJ: Physical activity and dietary behaviour in a population-based sample of British 10-year old children: the SPEEDY study (Sport, Physical activity and Eating behaviour: environmental Determinants in Young people). BMC Public Health 2008, 8:388.

32. Evenson KR, Catellier DJ, Gill K, Ondrak KS, McMurray RG: Calibration of two objective measures of physical activity for children. J Sport Sci 2008, 26:1557-1565.

33. Treuth MS, Schmitz K, Catellier DJ, McMurray RG, Murray DM, Almeida MJ, Going S, Norman JE, Pate R: Defining accelerometer thresholds for activity intensities in adolescent girls. Med Sci Sport Exerc 2004, 36:1259-1266.

34. Trost SG, Loprinzi PD, Moore R, Pfeiffer KA: Comparison of accelerometer cut points for predicting activity intensity in youth. Med Sci Sports ExerC 2011, 43:1360-1368.

35. Ridgers ND, Salmon J, Ridley K, O'Connell E, Arundell L, Timerio A: Agreement between activPAL and Actigraph for assessing children's sedentary time. Int J Behav Nutr Phys Act 2012, 9:15.

36. Sardinha LB, Andersen LB, Anderssen SA, Quiterio AL, Ornelas R, Froberg K, Riddoch $\mathrm{CJ}$, Ekelund $\mathrm{U}$ : Objectively measured time spent sedentary is associated with insulin resistance independent of overall and central body fat in 9- to 10-year-old Portuguese children. Diabetes Care 2008, 31:569-575.
37. Corder K, van Sluijs EM, Wright A, Whincup P, Wareham NJ, Ekelund U: Is it possible to assess free-living physical activity and energy expenditure in young people by self-report? Am J Clin Nutr 2009, 89:862-870.

38. Telford A, Salmon J, Jolley D, Crawford D: Reliability and validity of physical activity questionnaires for children: the children's leisure activities study survey (CLASS). Pediatr Exerc Sci 2004, 16:64-78.

39. Cole TJ, Bellizzi MC, Flegal KM, Dietz WH: Establishing a standard definition for child overweight and obesity worldwide: international survey. BMJ 2000, 320:1240-1243.

40. Bibby P, Shepherd J: Developing a New Classification of Urban and Rural Areas for Policy Purposes: The Methods. London, England: University of London; 2004.

41. Pulsford RM, Griew P, Page AS, Cooper AR, Hillsdon MM: Socioeconomic position and childhood sedentary time: evidence from the PEACH project. Int J Behav Nutr Phys Act 2013, 10:105.

42. Craig R, Mindell J, Hirani V (Eds): Health Survey for England 2008. Volume 1: Physical Activity and Fitness. Leeds: The NHS Information Centre for health and social care; 2009.

43. Nielsen Wire: US kids looking forward to "iHoliday". http://www.nielsen com/us/en/newswire/2011/us-kids-looking-forward-to-iholiday-2011.html.

44. The Nielsen Company: The cross-platform report - quarter 4, 2011 - US. http://www.nielsen.com/content/dam/corporate/us/en/reports-downloads/ 2012-Reports/nielsen-cross-platform-q4-2011.pdf.

45. The Nielsen Company: The cross-platform report - quarter 1, 2012 - US. http://www.nielsen.com/content/dam/corporate/us/en/reports-downloads/ 2012-Reports/Nielsen-Cross-Platform-Report-Q1-2012-final.pdf.

46. Barr-Anderson DJ, van den Berg P, Neumark-Sztainer D, Story M: Characteristics associated with older adolescents who have a television in their bedrooms. Pediatrics 2008, 121:718-724.

47. Ofcom: Communications infrastructure report. http://maps.ofcom.org.uk/ broadband/downloads/ofcom-uk-broadband-speed-report-2011.pdf.

48. Office for National Statistics: Regional trends, No 43 - rural and urban areas: comparing lives using rural/urban classifications. http://www.ons. gov.uk/ons/publications/index.html.

49. Granich J, Rosenberg M, Knuiman MW, Timperio A: Individual, social, and physical environment factors associated with electronic media use among children: sedentary behavior at home. J Phys Act Health 2011, 8:613-625

50. Jordan AB, Hersey JC, McDivitt JA, Heitzler CD: Reducing children's television-viewing time: a qualitative study of parents and their children. Pediatrics 2006, 118:e1303-e1310.

\section{doi:10.1186/1479-5868-10-137}

Cite this article as: Atkin et al.: Bedroom media, sedentary time and screen-time in children: a longitudinal analysis. International Journal of Behavioral Nutrition and Physical Activity 2013 10:137.

\section{Submit your next manuscript to BioMed Central and take full advantage of:}

- Convenient online submission

- Thorough peer review

- No space constraints or color figure charges

- Immediate publication on acceptance

- Inclusion in PubMed, CAS, Scopus and Google Scholar

- Research which is freely available for redistribution 